\title{
STUDIES IN IRON TRANSPORTATION AND METABOLISM. VII. EVIDENCE OBTAINED WITH RADIOACTIVE IRON THAT "EASILY SPLIT-OFF" BLOOD IRON IS AN ARTEFACT ${ }^{1}$
}

\author{
By MOISES GRINSTEIN AND CARL V. MOORE
}

\author{
(From the Department of Internal Medicine, Washington University, School of Medicine, \\ and the Barnes Hospital, Saint Louis, Missouri)
}

(Received for publication November 18, 1948)

Three different forms of blood iron have been described: hemoglobin iron, plasma (transport) iron, and "easily split-off" iron (E.S.Fe). The latter fraction, first studied by Barkan (1) and Lintzel (2), constitutes 5 to 10 per cent of the total blood iron. It derives its name from the fact that when blood is acidified and incubated with dilute hydrochloric acid the "easily split-off" fraction is ionized so that it can be separated from the remaining hemoglobin iron by dialysis or ultrafiltration. Lintzel and Radeff (3), and Legge and Lemberg (4) have demonstrated that E.S.Fe may be obtained in a similar manner from crystalline hemoglobin.

The amount of iron which can be "easily split off" from hemoglobin can be influenced in several ways. If blood or hemoglobin is treated with carbon monoxide, with reducing substances (i.e., ascorbic acid, $\mathrm{Na}_{2} \mathrm{~S}_{2} \mathrm{O}_{4}$ ), or is evacuated of its oxygen prior to the addition of dilute hydrochloric acid, the ionization produced by the acid is reduced considerably (4-6). In addition, changes in the concentration of acid alter the size of the fraction (7-9). It is largest when the concentration of $\mathrm{HCl}$ is approximately $0.03 \mathrm{~N}$ and decreases progressively as the amount of acid is increased to about $0.6 \mathrm{~N}$; further increases in $\mathrm{HCl}$ then cause comparatively little additional change. At concentrations of $0.1 \mathrm{~N}$, nitric and sulfuric acids ionize nearly twice as much of the iron in red cells as does hydrochloric acid (7).

The nature and biologic significance of E.S.Fe blood iron have remained in doubt. Some workers have regarded the fraction as an artefact produced by the oxidation of the prosthetic group of the hemoglobin molecule by oxygen evolved when

1 These studies were supported by research grants established in memory of Philipp Hunkel and Nathan Greenberg. acids are added to oxyhemoglobin. Barkan and Schales, however, presented evidence to show that E.S.Fe is derived from an intracorpuscular degradation product of hemoglobin, a bile pigmentiron-globin compound with an open porphyrin ring which they called pseudohemoglobin $(6,10) .^{2}$ This explanation was altered by Legge and Lemberg (4). After confirming the observation (6, $10)$, that about two-thirds of the E.S.Fe fraction was split-off only in the presence of oxygen and in the absence of reducing substances while the remaining third was ionized even in inert gases or $\mathrm{CO}$, they concluded that the larger of these two fractions is an artefact while the smaller is at least partially attributable to a bile pigment-hemoglobin which gives rise to bile pigments when treated with acids. Even though these interpretations differ, both groups of investigators believe that at least a portion of E.S.Fe is derived from an intraerythrocytic pigment formed as one of the initial steps in the breakdown of hemoglobin to bilirubin.

On the other hand, the experiments with radioactive iron reported by Miller and Hahn (13) suggested that E.S.Fe is really an artefact. These observers administered radioactive iron to dogs and observed that several days later there was as much of the isotope present in the E.S.Fe of red blood cells as was found two weeks later. If all of the E.S.Fe is derived from a degradation pro-

2 Pseudohemoglobin was prepared in vitro by Barkan and Schales by oxidizing oxyhemoglobin with hydrogen peroxide in the presence of cyanide (10). Legge and Lemberg (4), in many of their studies, used choleglobin prepared by coupled oxidation of hemoglobin and ascorbic acid (11). In both compounds, the alpha- $\mathrm{CH}=$ bridge of the heme molecule is open, and iron is readily dissociated by dilute acids. Both may be classified as verdohemoglobins. Liébecq regards them as being very similar, if not identical substances (12). 
duct of hemoglobin, the fraction found in newly formed erythrocytes should not have contained radioactive iron. These studies do not invalidate Legge's and Lemberg's concept, however, because according to them the major part of E.S.Fe is an artefact and only a small portion comes from a hemoglobin breakdown product. In order to investigate this possibility more thoroughly with the tracer technique, it would be necessary to follow the concentration of radioactive iron in the E.S.Fe fraction throughout the life of the red blood cell. This was done in the observations described below. If the major part of E.S.Fe is an artefact, the radioactive iron would be expected to appear as promptly in this fraction as in hemoglobin and its concentration should remain constant for weeks. However, if a small portion of E.S.Fe is derived from a hemoglobin breakdown product within old red cells (4), then as the erythrocytes reach the end of their survival period, a sharp increase should occur in the concentration of isotopic iron in the E.S.Fe fraction. This result would constitute convincing evidence that E.S.Fe was derived from a compound formed within the red blood cell as an intermediate step in the transition of hemoglobin to bilirubin. Such an increase in the radioactivity of E.S.Fe in old red cells, however, could not be demonstrated in the present study.

\section{MATERIAL AND METHODS}

Tracer doses of radioactive iron were administered to eight human subjects and to three dogs. The human subjects were: 1 ) three healthy members of the laboratory staff, 2) one woman with hypochromic anemia, 3) three patients with Addisonian pernicious anemia in relapse receiving specific therapy, and 4) one man with malignant hypertension. All of the human subjects except two were given one single injection of radioiron $\left(\mathrm{Fe}^{\mathrm{es}}\right)$ intravenously as ferrous ascorbate. ${ }^{3} \mathrm{~F}$. M. received a similar preparation but was given two injections on successive days. One patient (S. W.) took a mixture of $\mathrm{Fe}^{\infty \mathrm{o}}$ and $\mathrm{Fe}^{\mathrm{ss}}$ orally as ferrous chloride. 4 The three dogs were made anemic by repeated phlebotomies prior to being given a single dose of radioiron (mixture of $\mathrm{Fe}^{\mathrm{so}}$

\footnotetext{
${ }^{3} \mathrm{Fe}^{\mathrm{5}}$ of high specific activity was obtained by deuteron bombardment of a cobalt target in the Washington University Cyclotron. The authors are indebted to the cyclotron staff for preparation of the material. Techniques for separation of $\mathrm{Fe}^{\mathrm{io}}$ from the target and for preparation of ferrous ascorbate have already been described $(14,15)$.

4 The mixture of isotopes $\mathrm{Fe}^{\mathrm{ss}}$ and $\mathrm{Fe}^{\infty}$ was obtained from the Clinton Laboratories, Oak Ridge, Tennessee.
}

and $\mathrm{Fe}^{\mathrm{s}}$ ), either by stomach tube or intravenously as ferric chloride.

In each series of observations except that done on F. M., blood was obtained periodically for determination of total and of radioactive iron in both whole blood and the E.S.Fe fraction. The three normal subjects and two of the three dogs were followed for more than 120 days. Blood was collected in iron-free tubes which contained a dry mixture of potassium and ammonium oxalate as anti-coagulant. From the remaining subject (F. M.), $400 \mathrm{ml}$. of blood were removed on the seventh day following the first of two intravenous injections of ferrous ascorbate containing $\mathrm{Fe}^{\mathrm{s0}}$ and $\mathrm{Fe}^{\mathrm{s5}}$. An ordinary transfusion bottle containing acid citrate-dextrose solution was used for the collection, and the blood was then divided into $25 \mathrm{ml}$. aliquot samples, each placed in a tightly stoppered sterile flask. These smaller bottles were stored in a refrigerator at $4^{\circ} \mathrm{C}$; ; at intervals one of these small flasks was removed for measurement of total blood iron and E.S.Fe.

Total blood iron (T.B.Fe) was determined by the thiocyanate method (7) on an aliquot of the solution obtained after digestion of whole blood with concentrated $\mathrm{H}_{2} \mathrm{SO}_{4}$ and $30 \% \mathrm{H}_{2} \mathrm{O}_{2}$. The method used for measuring E.S.Fe was that of Barkan and Walker (16). Whole blood was acidified to $0.4 \% \mathrm{HCl}$, incubated for 16 to 24 hours at $37^{\circ} \mathrm{C}$., and precipitated with $20 \% \mathrm{CCl}_{8} \mathrm{COOH}$; an aliquot portion of the supernatant solution was used for the colorimetric determination. In some instances, blood was saturated with $\mathrm{CO}$ prior to the addition of the $\mathrm{HCl}$.

Aliquot samples of the whole blood digest and of the E.S.Fe supernatant fluid were taken for radioiron determinations. The latter aliquot was then digested with $\mathrm{H}_{2} \mathrm{SO}_{4}$ and $\mathrm{H}_{2} \mathrm{O}_{2}$. Iron from both digest mixtures was precipitated as $\mathrm{Fe}(\mathrm{OH})_{3}$ and electroplated on copper discs in the manner previously described (14). Radioactivity was measured with a Kip type Geiger-Müller counter. Correction for the decay of the radioiron was not necessary since determination of the radioactivity in standard solutions and in all the samples obtained at intervals on the same subject were finally made on the same day at the end of the study. Blood volume was assumed to be $80 \mathrm{ml}$. per kilogram of body weight.

Results were expressed both as absolute values and in terms of radioactivity per $\mathrm{mgm}$. of total iron:

1) Counts/min./mgm. T.B.Fe

$$
=\frac{\text { Radioactivity } / 100 \mathrm{ml} \text {. whole blood }}{\text { Total iron in } \mathrm{mgm} . / 100 \mathrm{ml} \text {. whole blood }}
$$

2) Counts/min./mgm. E.S.Fe

$$
=\frac{\text { Radioactivity } / 100 \mathrm{ml} \text {. in E.S.Fe fraction }}{\text { Total iron in } \mathrm{mgm} . \text { in E.S.Fe fraction } / 100 \mathrm{ml} . \text { blood }}
$$

RESULTS

\section{Normal human subjects}

The results obtained for the three normal subjects followed for 124 days are charted in Figures 
1,2 , and 3. The appearance of radioiron in the blood indicated prompt and relatively complete utilization of the tracer dose for hemoglobin synthesis; the utilization curves for the three subjects are comparable to those previously reported from this laboratory (15).

The radioactivity per milligram of iron was practically the same in both the T.B.Fe and in the E.S.Fe fraction. There was no tendency for the radioactivity in the E.S.Fe fraction to increase as the red blood cells containing the tagged iron became older. Because Legge and Lemberg concluded that the biologically significant portion of E.S.Fe was contained in that part which could be dissociated even in the presence of inert gases or $\mathrm{CO}$, the radioactivity in E.S.Fe separated after complete saturation of blood with $\mathrm{CO}$ was determined on the 124th day for each of these subjects.
In such a determination, any tendency for a specific increase in the radioactivity of the fraction would be magnified. Even under these circumstances, however, there was no tendency for the radioactivity in E.S.Fe to increase (Table I).

\section{Dogs made anemic by repeated bleeding}

Two of the three dogs made anemic by repeated bleeding prior to the injection of radioiron were studied for 145 days (Figures 4, 5). In Dog I, 80 per cent of the injected iron was used rapidly for hemoglobin formation; the gradual decrease in the amount of circulating isotope can be explained by the fact that this animal lost blood regularly from its gastro-intestinal tract. The utilization curve for Dog II (Figure 5) was normal in shape but only about 60 per cent of the injected dose appeared in the circulating blood.

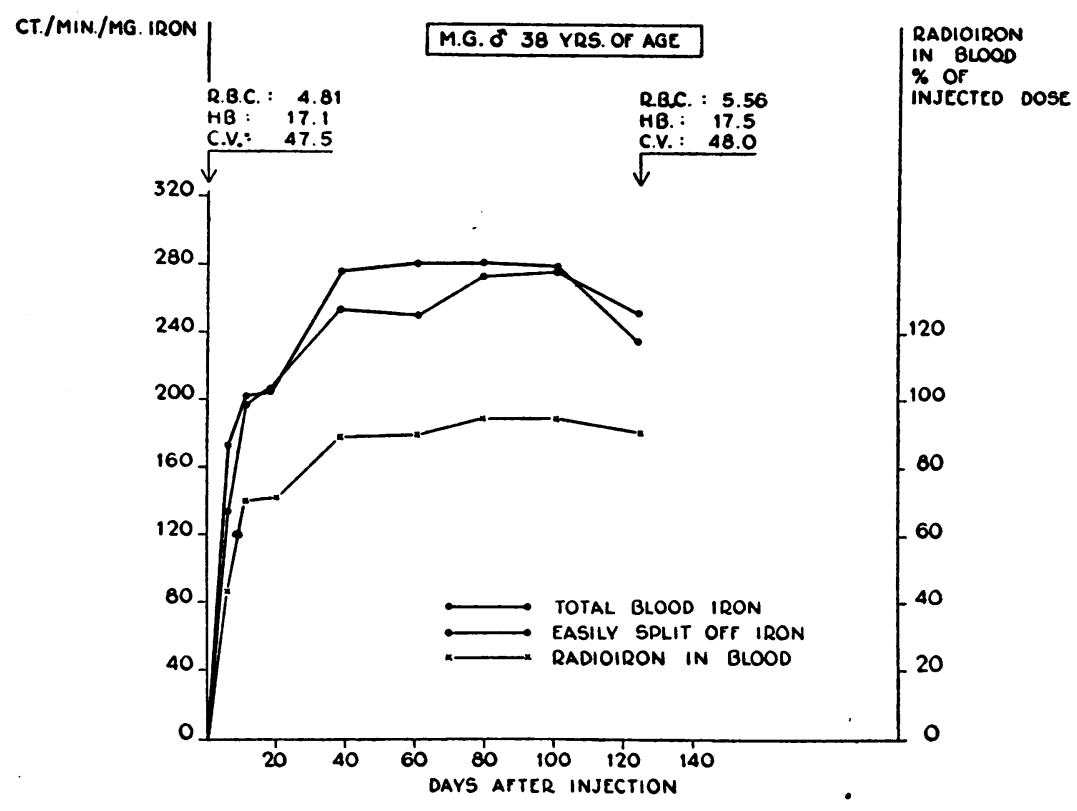

Fig. 1. Concentration of Radioiron Appearing in the Whole Blood and "Easily Split-Off" Blood Iron Fraction of a Healthy Adult Man After InTravenous INJECTION OF $\mathrm{FE}^{\text {so }}$

$5.6 \mathrm{mgm}$. of radioiron $\left(\mathrm{Fe}^{\infty}\right)$ having $7,200,000$ counts per minute were given intravenously as ferrous ascorbate.

The following explanations apply to Figures 1 to 8 inclusive:

"Radioiron in blood," refers to the total radioactive iron circulating in the total blood volume. Values are recorded in terms of the per cent of the dose found in the blood (scale on right side of each chart).

"Total blood iron," and "easily split-off iron," refer to the activity of radioiron in counts/min./mgm. Fe (scale on left side of each chart).

R.B.C. $=$ red blood cell count in millions per cu. $\mathrm{mm}$.

$\mathrm{Hb} .=$ hemoglobin in grams per $100 \mathrm{ml}$. blood.

C.V. = volume of packed red blood cells in ml. per $100 \mathrm{ml}$. blood. 


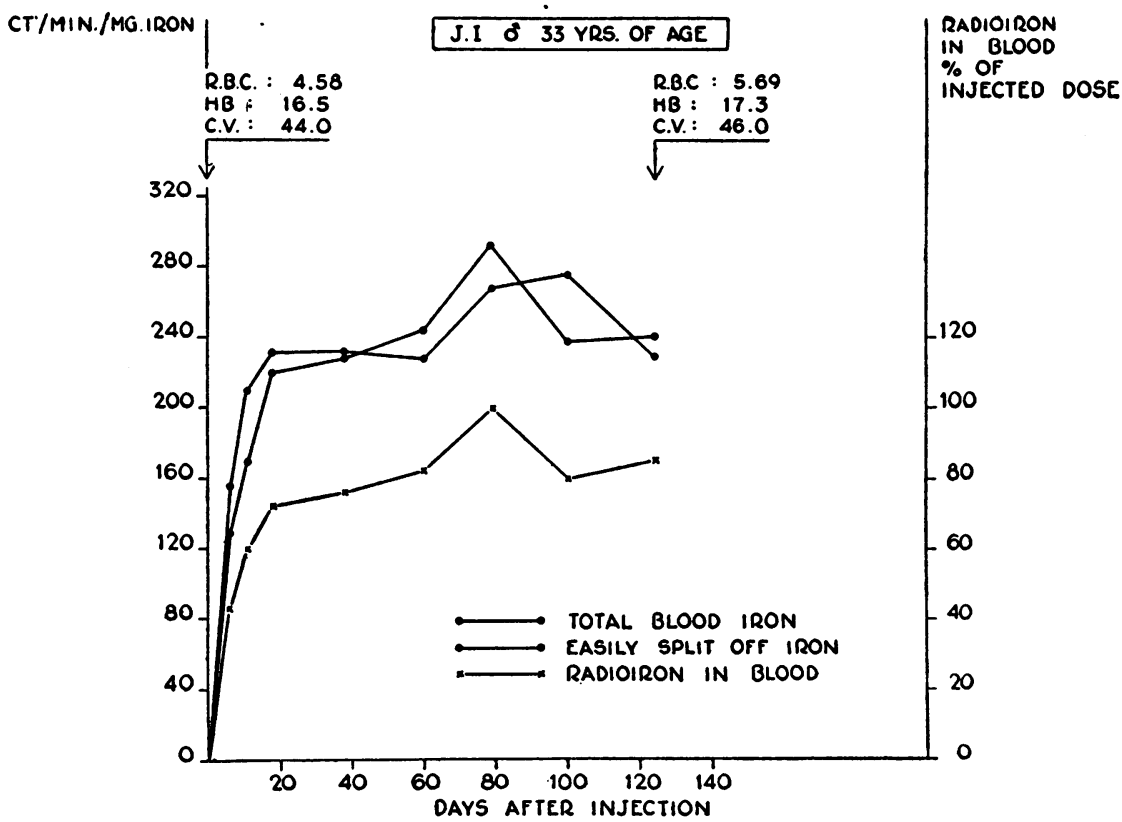

Fig. 2. Concentration of Radiotron Appearing in Whole Blood and "Easily Split-Off" Blood Iron of a Healthy Adult Man After Intravenous Injection OF $\mathrm{FE}^{\mathrm{s}}$

$5.6 \mathrm{mgm}$. of radioiron $\left(\mathrm{Fe}^{50}\right)$ having $7,200,000$ counts per minute were given intravenously as ferrous ascorbate.

(See also explanations for Figure 1.)

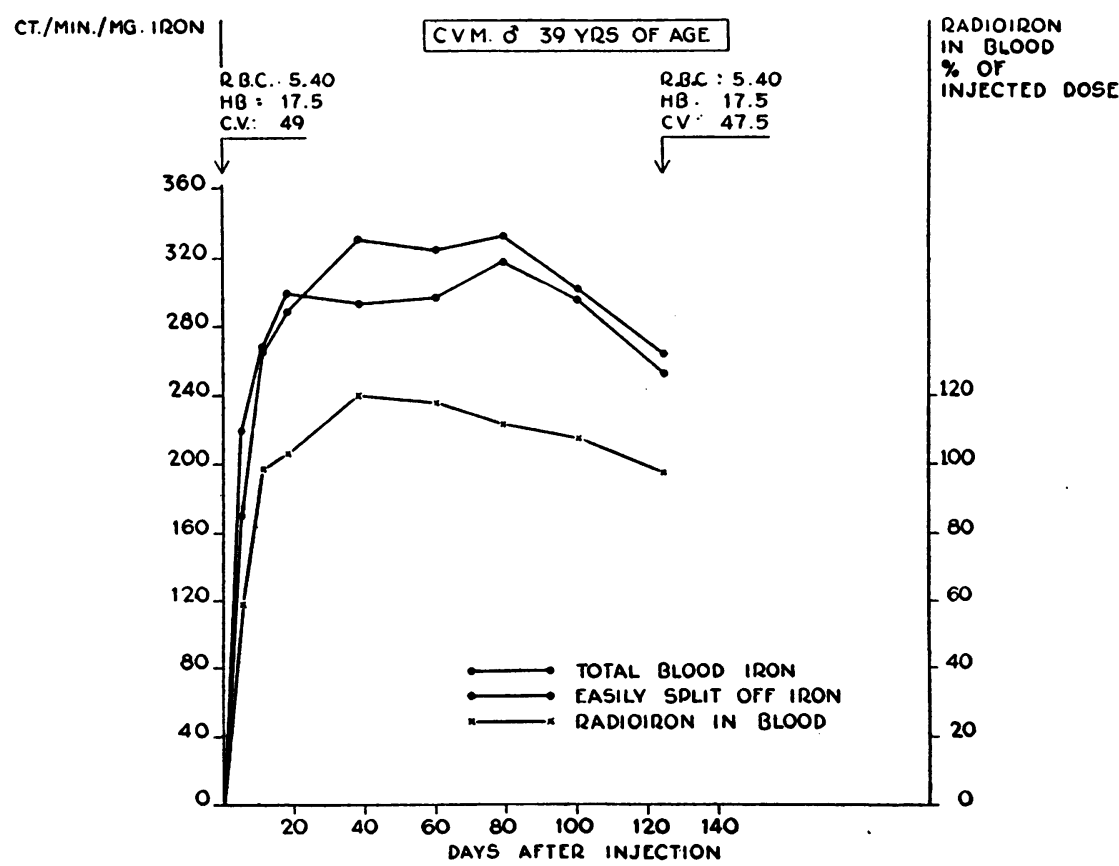

Fig. 3. Concentration of Radioiron Appearing in Whole Blood and "Easily Split-Off" Blood Iron of a Healthy Adult Man After Intravenous Injection of $\mathrm{FE}^{\mathrm{\infty}}$

$5.6 \mathrm{mgm}$. of radioiron $\left(\mathrm{Fe}^{\infty 0}\right)$ having $7,200,000$ counts per minute were given intravenously as ferrous ascorbate.

(See also explanations for Figure 1.) 


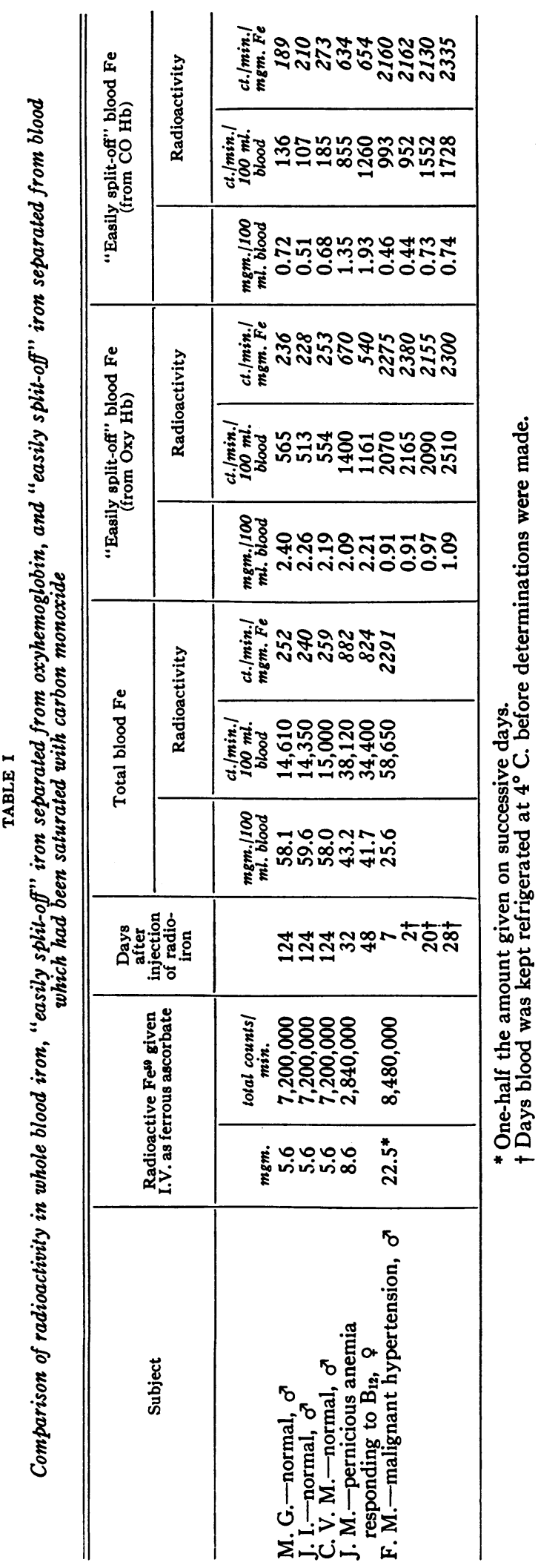

In neither instance was there any significant difference between the radioactivity per milligram of T.B.Fe and that per milligram of E.S.Fe. The greatest discrepancies appeared on days 24 , 41 , and 62 in Dog I. The significant fact, however, is that there was no tendency for the radioactivity in the E.S.Fe fraction to increase as the red cells containing the isotope grew older. In the legends to Figures 4 and 5 are tabulated representative blood counts obtained during the course of the experiment. From these data it is evident that the hemoglobin increased in each animal as it recovered from the anemia induced by hemorrhage. This increase in hemoglobin caused a dilution of the radioiron in the blood and accounts for the gradual decrease in the radioactivity per milligram $\mathrm{Fe}$ in both the T.B.Fe and E.S.Fe.

In Dog III, a hemorrhagic anemia was also induced. This animal was followed for only 22 days after he had been given radioiron orally; E.S.Fe was determined after blood had been saturated with $\mathrm{CO}$. The counts per minute per milligram of iron in the T.B.Fe fraction agreed very well with the activity in the fraction separated after exposure to $\mathrm{CO}$ (Table II).

TABLE II

Comparison between the concentration of radioactive iron in whole blood and in the "easily split-off" blood iron fraction, determined after saturation with carbon monoxide Dog III

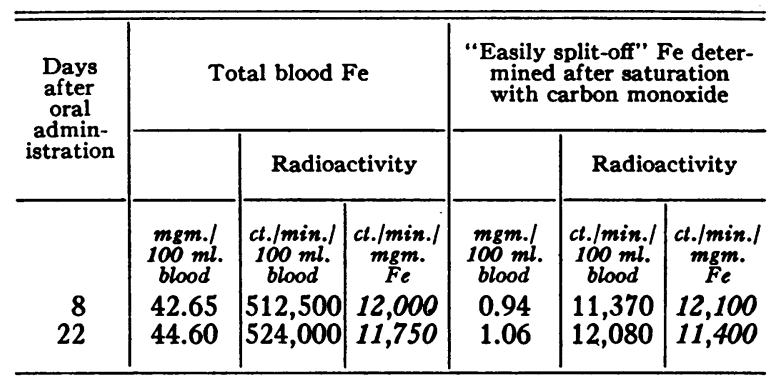

The animal had been made anemic by repeated bleeding prior to administration of radioiron. $47.6 \mathrm{mgm}$. of radioactive iron $\left(\mathrm{Fe}^{56}\right.$ and $\mathrm{Fe}^{59}$ ) were given by stomach tube, as ferric chloride. Total counts $=11,900,000 / \mathrm{min}$.

\section{Human subject with hypochromic anemia}

A study similar to that described in the two previous sections was made on a woman, S. W., 35 years of age, with a severe degree of hypochromic anemia (Figure 6). In this instance, the radioiron was given orally. The absorbed isotope 


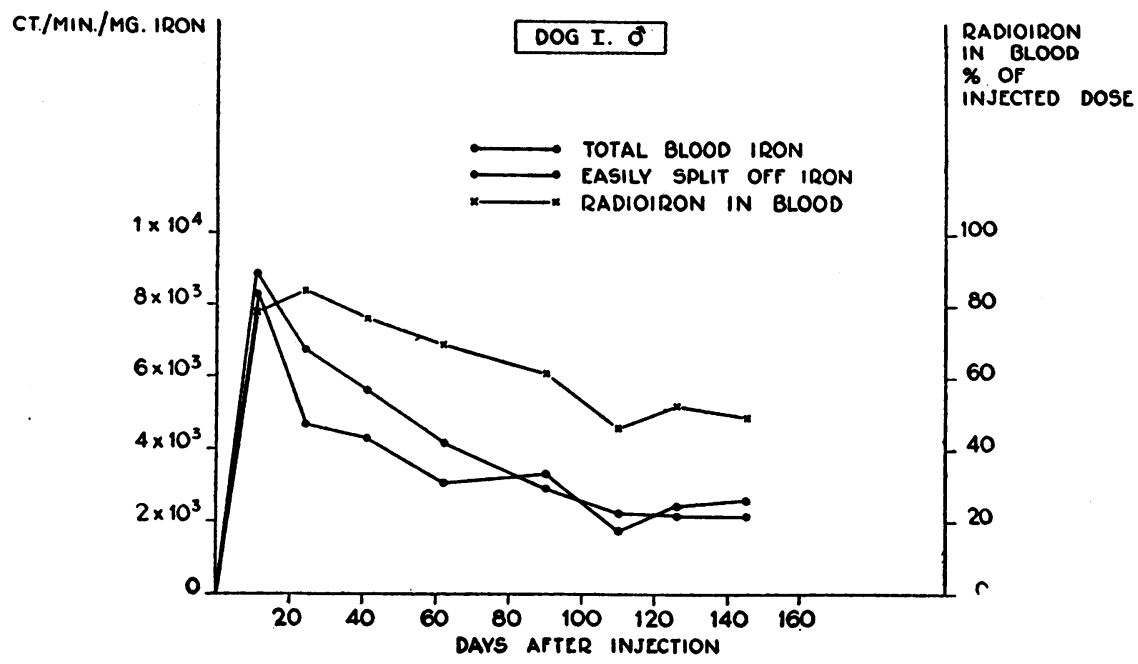

Fig. 4. Concentration of Radiotron Appearing in Whole Blood and "Easily Split-Off" Blood Iron of a Dog Made Anemic by Induced Hemorrhage

$17.4 \mathrm{mgm}$. of radioiron (mixture of $\mathrm{Fe}^{\mathrm{ss}}$ and $\mathrm{Fe}^{\mathrm{es}}$ ) were given intravenously as ferric chloride. Total counts $=7,200,000 / \mathrm{min}$.

$\begin{array}{rccc}\text { Day } & \text { R.B.C. } & \text { Hb. } & \text { C.V. } \\ 1 & 3.26 & 6.5 & 22.5 \\ 11 & 5.48 & 10.3 & 35.5 \\ 41 & 6.22 & 14.4 & 46.0 \\ 90 & 7.77 & 15.8 & 49.0 \\ 145 & 7.20 & 15.9 & 49.5\end{array}$

(See also explanations for Figure 1.)

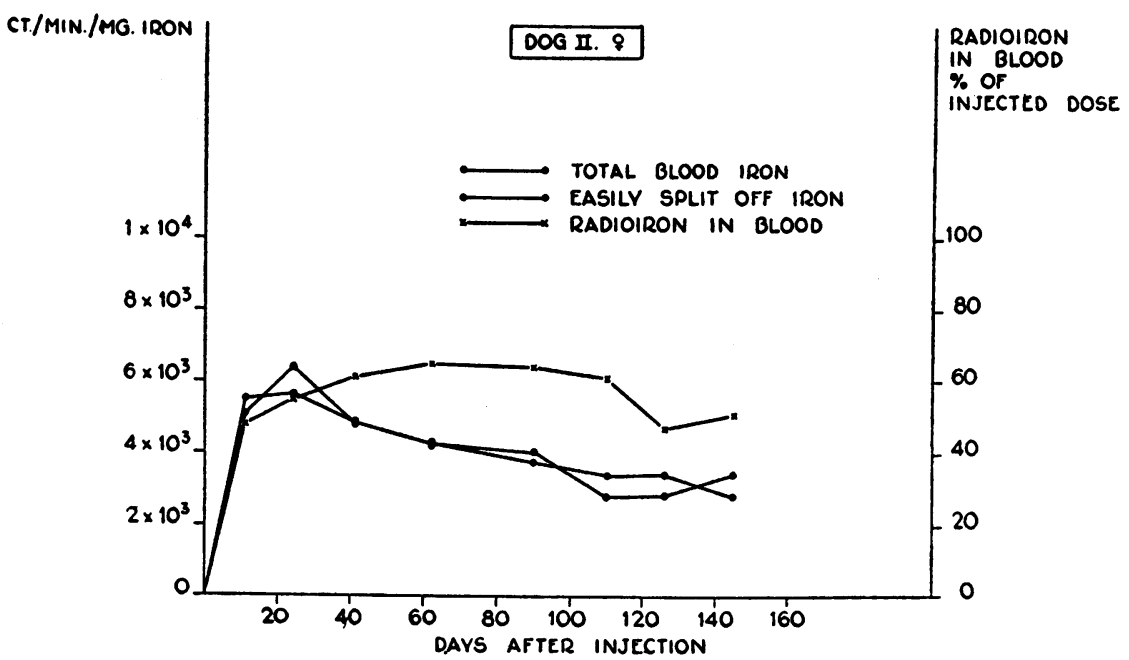

Fig. 5. Concentration of Radiotron Appearing in Whole Blood and "Easily Split-Off" Blood Iron of a Dog Made Anemic by Induced Hemorrhage

$34.8 \mathrm{mgm}$. of radioiron (mixture of $\mathrm{Fe}^{\mathrm{ss}}$ and $\mathrm{Fe}^{\mathrm{s}}$ ) were given intravenously as ferric chloride. Total counts $=14,400,000 / \mathrm{min}$.

$\begin{array}{rcrl}\text { Day } & \text { R.B.C. } & \text { Hb. } & \text { C.V. } \\ 1 & 3.41 & 6.5 & 23 \\ 11 & 5.21 & 10.2 & 35.5 \\ 41 & 6.8 & 15.0 & 46 \\ 90 & 7.35 & 15.6 & 47 \\ 145 & 6.9 & 18.4 & 50\end{array}$

(See also explanations for Figure 1.) 


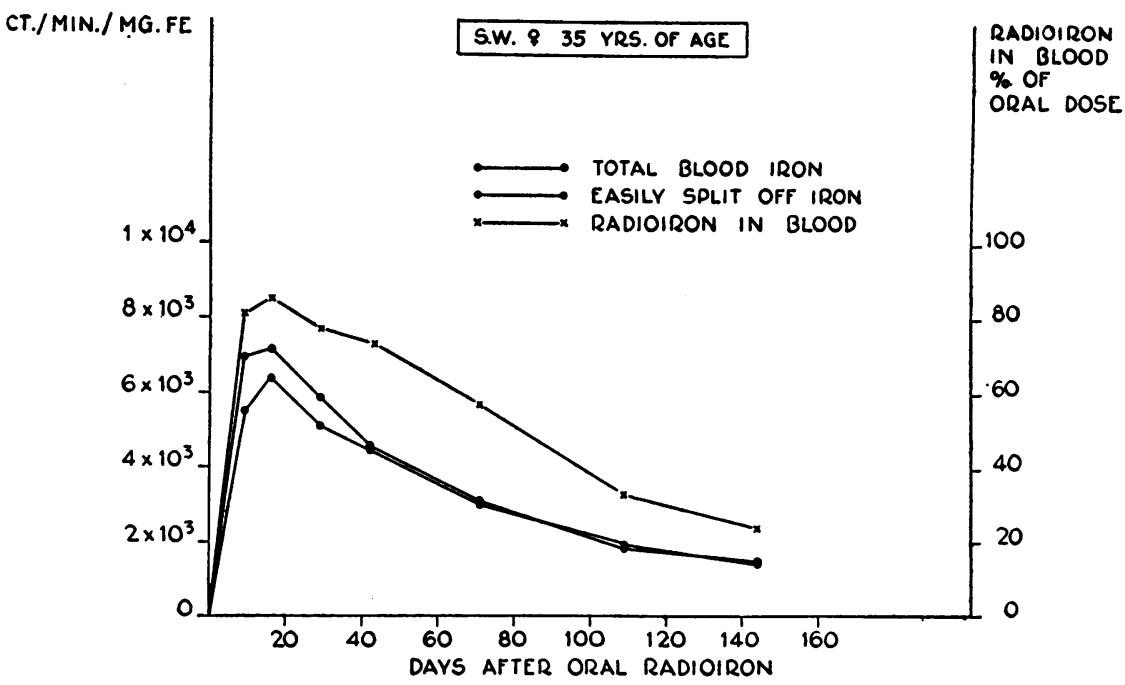

Fig. 6. Appearance of Radioiron in the Whole Blood and "Easily Split-Off" Blood Iron fraction of a Patient with Hypochromic Anemia

$55 \mathrm{mgm}$. of radioiron (mixture of $\mathrm{Fe}^{\mathrm{ss}}$ and $\mathrm{Fe}^{\mathrm{s}}$ ) given orally as ferrous chloride. Total counts $=32,000,000 / \mathrm{min}$. Patient was treated with $2.4 \mathrm{gm}$. of ferrous gluconate daily after the 16th day.

$\begin{array}{rrrl}\text { Day } & \text { R.B.C. } & \text { Hb. } & \text { C.V. } \\ 1 & 4.41 & 8.6 & 28 \\ 16 & 4.11 & 8.7 & 27.5 \\ 42 & 5.11 & 10.1 & 35 \\ 71 & 4.37 & 12.4 & 38 \\ 144 & 3.82 & 10.1 & 32\end{array}$

(See also explanations for Figure 1.)

was utilized promptly for hemoglobin synthesis, but by the time observations were discontinued on the 144th day the amount of radioiron in her peripheral blood had decreased to approximately one-third of the peak value. This fall was unquestionably caused by menorrhagia with the loss of large amounts of blood.

As in the normal subjects and in the dogs, the radioactivity per milligram of iron in both T.B.Fe and E.S.Fe remained almost identical during the whole period of study.

\section{Patients with Addisonian pernicious anemia}

In order to study the differences which might occur in the radioactivity present in T.B.Fe and E.S.Fe during the first few days after administration of the isotope, it was necessary to select subjects who were manufacturing hemoglobin at an accelerated rate. This precaution was required to make certain that the amount of radioiron pres- ent in the fractions during the first few days would be large enough to count. Accordingly, radioiron was given intravenously to three patients with Addisonian pernicious anemia during the period of accelerated erythropoiesis following the institution of specific therapy. The results for two of these observations are charted in Figures 7 and 8. Utilization of the injected isotope was prompt and approximately complete. In the first subject ( $O$. A. W., Figure 7) more radioactivity was discovered during the first two days per milligram of iron in the E.S.Fe fraction than in the T.B.Fe. As will be emphasized later, this increase was probably due to the radioactive iron remaining in the plasma. After the first 48 hours, the radioactivity per milligram of iron in E.S.Fe remained slightly but consistently lower than in T.B.Fe.

Determinations of E.S.Fe after blood had been saturated with carbon monoxide were made on the second patient (J. M., Figure 8), This patient was the only one of all the subjects studied in 


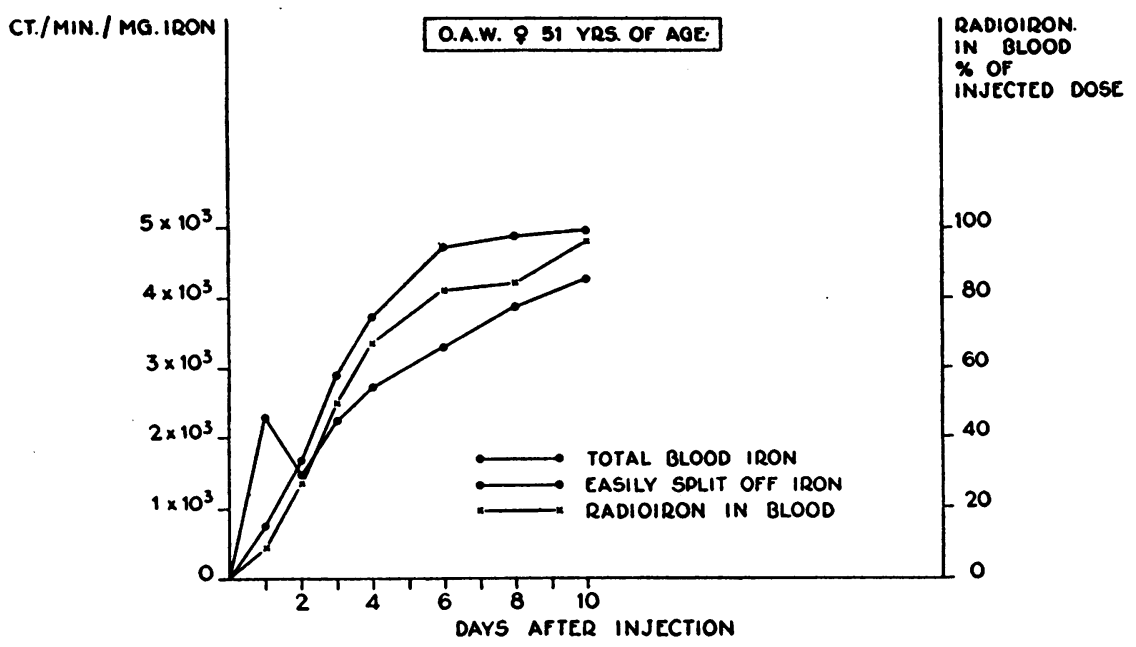

Fig. 7. Appearance of Radiotron in the Whole Blood and "Easily SplitOff" Blood Iron Fraction of a Patient with Pernicious Anemia during ReSPONSE TO LIVER Extract

Liver extract in therapeutic doses had been given approximately two weeks prior to the injection of radioiron. $6.5 \mathrm{mgm}$. $\mathrm{Fe}^{\infty}$ as ferrous ascorbate injected intravenously. Total counts : $10,980,000$.

\begin{tabular}{|c|c|c|}
\hline $\begin{array}{c}\text { Day } \\
1\end{array}$ & $\begin{array}{l}\text { R.B.C. } \\
2.75\end{array}$ & $\begin{array}{c}\text { Hb. } \\
7.8\end{array}$ \\
\hline 10 & 3.77 & 11.3 \\
\hline
\end{tabular}

(See also explanations for Figure 1.)

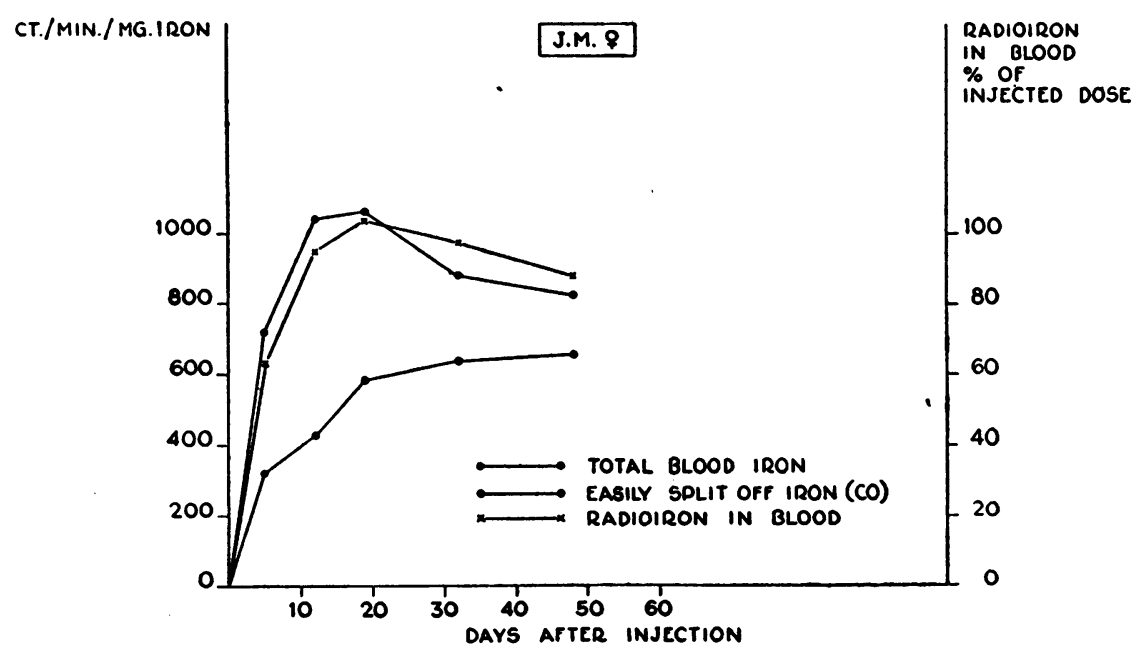

Fig. 8. Appearance of Radiotron in the Whole Blood and "Easily SplitOff" Blood Iron Fraction of a Pattent with Pernicious Anemia during ReSPONSE TO VITAMIN $B_{12}$

Three weeks prior to the radioiron $46 \mu \mathrm{g}$. of Vitamin $B_{12}$ had been given intramuscularly. Five mgm. of $\mathrm{Fe}^{\mathrm{m}}$ as ferrous ascorbate injected intravenously. Total counts : $2,840,000$. Red blood cell values were increasing rapidly at the time the iron was administered.

(See also explanations for Figure 1.) 
whom the radioactivity per milligram $\mathrm{Fe}$ of E.S.Fe differed significantly from that in T.B.Fe. It was consistently lower during the 48 days of observation; further study became impossible when the patient left the hospital. The reason for this different result is not clear. That it was not due to the fact that determinations were done in $\mathrm{CO}$ was demonstrated on the 32nd and 48th days when E.S.Fe was measured in the usual manner (Table I) ; a similar lower activity was found.

The radioiron in plasma during the first 48 hours after injection of radioactive ferrous ascorbate was followed in the third subject (W.S., Table III).

TABLE III

Radioactive $\mathrm{Fe}$ in the plasma of a patient with pernicious anemia (W.S.) during first 48 hours after intravenous injection of $\mathrm{Fe}^{59}$
Time following radioiron I.V. hours

15

24
48
Counts $/ \mathrm{min} . / 100 \mathrm{ml}$. plasma

6380

3120

880
Five mgm. $\mathrm{Fe}^{59}$ given I.V. as ferrous ascorbate 21 days after initiation of liver therapy. Red blood cell values were rising rapidly during the time these observations were made. Total counts administered $=7,900,000$.

It can be seen that relatively large amounts of radioactivity were present in the plasma during this period. Since the plasma iron is also ionized by the concentrations of acid used for determination of E.S.Fe, the radioactivity in this latter fraction would tend to be falsely high during the first several days after injection of radioactive iron. This fact probably accounts for the high concentrations of $\mathrm{Fe}^{59}$ in te E.S.Fe fraction observed at 24 and 48 hours in O. A. W. (Figure 7).

\section{Effect of storing blood}

If hemoglobin transformation to bilirubin begins within the red blood cell by formation of a verdohemoglobin, then it is possible that the intracorpuscular degradation of hemoglobin would take place more rapidly in stored blood. Should this occur in blood which contains hemoglobin tagged with $\mathrm{Fe}^{59}$, one would expect that the radioactivity per milligram of iron would progressively increase in the E.S.Fe fraction. To test this possibility, blood obtained from F. M., an adult male with malignant hypertension, was collected on the seventh day following the first of two injections of tagged ferrous ascorbate. As described in the Methods Section, the blood was stored in small flasks at $4^{\circ} \mathrm{C}$. On the second, 20th, and 28th days, flasks were removed for analysis. While there was a tendency for the total amount of iron in the E.S.Fe fraction to increase, particularly when $\mathrm{CO}$ was used to saturate the blood, there was no appreciable change in the radioactivity per milligram of iron (Table I). Observations had to be terminated after 28 days because the cells became hemolyzed.

\section{DISCUSSION}

In all observations except those made on one of the patients with pernicious anemia (J. M., Figure 8), there was extremely close correlation between the radioactivity per milligram of iron in whole blood and that in the "easily split-off" fraction. Radioiron appeared just as promptly in the E.S.Fe fraction as in the T.B.Fe. There was, furthermore, no tendency for the concentration of radioactivity in the E.S.Fe to increase as erythrocytes aged and reached the end of their life span, as would be expected if E.S.Fe bore any relationship to the formation of an intracorpuscular degradation product of hemoglobin. The same type of result was obtained whether E.S.Fe was determined on oxygenated blood or on blood which had been saturated with carbon monoxide prior to the addition of acid. The data indicate that "easily split-off" blood iron as defined by Barkan is an artefact and originates entirely or almost entirely from intact hemoglobin.

These observations do not, however, eliminate the possibility that a small fraction of E.S.Fe may originate from an intraerythrocytic verdohemoglobin like choleglobin or pseudohemoglobin. It is conceivable that the methods used were not delicate enough to detect the small increase in concentration of radioiron which would occur in E.S.Fe under these circumstances as the cells aged. That such a possibility exists, is suggested by Lemberg's and Legge's (17) demonstration that: (1) normal human red blood cells contain 1 to $5 \mu \mathrm{g}$. of biliverdin combined as choleglobin per milliliter of cells; and (2) the injection of phenylhydrazine into rabbits causes an increase in the choleglobin of their erythrocytes. Gardikas, Kench and Wilkinson (18), however, have recently criti- 
cized the technique used by Lemberg and Legge on the grounds that choleglobin might well have been formed during their determinations. Gardikas et al. repeated the observations under anaerobic conditions and failed to detect choleglobin in 12 separate samples of blood. Furthermore, except in one instance each of leukemia, pernicious anemia, and obstructive jaundice, they failed to demonstrate the pigment in blood taken from patients with pernicious anemia, leukemia, hemolytic anemias, polycythemia, or hepatic and obstructive jaundice. At the present time, therefore, there remains no unchallenged demonstration that any pigment formed as a degradation product of hemoglobin regularly occurs within red blood cells. There is no convincing evidence that the transition of hemoglobin to bilirubin begins as an intraerythrocytic process. It is emphasized that even if such a pigment were found to be present, it would account for only a small fraction of E.S.Fe and would not seriously affect the conclusion that the E.S.Fe fraction is an artefact.

\section{SUMMARY AND CONCLUSIONS}

At intervals following the administration of radioactive iron to normal human subjects, to patients with hypochromic and pernicious anemias, and to dogs made anemic by repeated bleeding, the concentration of radioactive iron in the total blood iron and in "easily split-off" iron was measured. In some of the observations "easily split-off" iron was determined on samples of blood which had been saturated with carbon monoxide prior to the addition of acid. In one experiment, citrated blood was stored at $4^{\circ} \mathrm{C}$. and determinations were made at intervals for 28 days. Radioactivity appeared in the "easily split-off" blood iron fraction just as promptly and in the same concentration as it appeared in hemoglobin. No correlation was noted between the radioactivity in the "easily splitoff" iron fraction and ageing of the red blood cells. It is concluded that "easily split-off" blood iron, whether determined on oxygenated blood or on blood saturated with carbon monoxide, is an artefact. The possibility exists that a small fraction of the "easily split-off" iron may be derived from intraerythrocytic verdohemoglobin, but no convincing evidence exists for the presence in red cells of such a pigment nor for the belief that degradation of hemoglobin begins within the erythrocyte.

\section{BIBLIOGRAPHY}

1. Barkan, G., Eisenstudien. I. Mitteilung. Zur Frage der Einwirkung von Verdauungsfermenten auf das Hämoglobineisen. Ztschr. f. physiol. Chem., 1925, 148, 124.

2. Lintzel, W., Zur Frage des Eisenstoff wechsels. I. Das Verhalten des Blutfarbstoffes bei künstlicher Verdauung. Ztschr. f. Biol., 1925, 83, 289.

3. Lintzel, W., and Radeff, T., Uber die Hämatinbildung aus CO-Hämoglobin und Oxyhämoglobin durch verdünnte Säuren. Biochem. Ztschr., 1928, 203, 212.

4. Legge, J. W., and Lemberg, R., Coupled oxidation of ascorbic acid and haemoglobin; the "labile iron" in blood and its increase during choleglobin formation. Biochem. J., 1941, 35, 353.

5. Barkan, G., and Berger, E., Differenzierung des leicht abspaltbaren Bluteisens auf Grund seiner Reaktion mit Kohlenoxyd und Sauerstoff. Arch. f. exper. Path. u. Pharmakol., 1928, 136, 278.

6. Barkan, G., and Schales, O., Eisenstudien. 13. Chemischer Aufbau und physiologische Bedeutung des "leicht abspaltbaren" Bluteisens. Ztschr. f. physiol. Chem., 1937, 248, 96.

7. Moore, C. V., Studies in iron transportation and metabolism; chemical methods and normal values for plasma iron and "easily split-off" blood iron. J. Clin. Invest., 1937, 16, 613.

8. Venndt, Helge, Untersuchungen über den Abbau des Hämoglobins bei Einwirkung verdünnter Säuren. Ztschr. f. physiol. Chem., 1940, 263, 162.

9. Barkan, G., and Schales, O., Origin of ionized iron after action of acids on blood and influence of carbon monoxide. Proc. Soc. Exper. \& Biol. Med., 1942, 50, 74.

10. Barkan, G., and Schales, O., Eisenstudien. 14. Bildungsmöglichkeiten und Eigenschaften der Pseudohämoglobine. Ztschr. f. physiol. Chem., 1938, 253, 83.

11. Lemberg, R., Legge, J. W., and Lockwood, W. H., Coupled oxidation of ascorbic acid and haemoglobin; formation and properties of choleglobin. Biochem. J., 1941, 35, 328.

12. Liébecq, C., La pseudohémoglobine et le catabolisme des composés hémiques. Experientia, 1948, 4, 56.

13. Miller, L. L., and Hahn, P. F., The appearance of radioactive iron as hemoglobin in the red cell. The significance of "easily split" iron. J. Biol. Chem., 1940, 134, 585.

14. Moore, C. V., Dubach, R., Minnich, V., and Roberts, H. K., Absorption of ferrous and ferric radio- 
active iron by human subjects and by dogs. J. Clin. Invest., 1944, 23, 755.

15. Dubach, R., Moore, C. V., and Minnich, V., Studies in iron transportation and metabolism; utilization of intravenously injected radioactive iron for hemoglobin synthesis, and an evaluation of the radioactive iron method for studying iron absorption. J. Lab. \& Clin. Med., 1946, 31, 1201.
16. Barkan, G., and Walker, B. S., Determination of serum iron and of pseudohemoglobin iron with ortho-phenanthroline. J. Biol. Chem., 1940, 135, 37.

17. Lemberg, R., and Legge, J. W., Intracorpuscular bile pigment formation. Australian J. Exper. Biol. \& M. Sc., 1942, 20, 65.

18. Gardikas, C., Kench, J. E., and Wilkinson, J. F., Choleglobin formation in the erythrocyte. Nature, 1948, 161, 607. 